\title{
INFLUENCE OF MECHANICAL ANISOTROPY IN LOW CARBON MICROALLOYED STEEL
}

The energy industry is one of the most discussed topics in modern days. Among the critical areas belongs the production and sale of energy, including fuel extraction, manufacturing, refining and distribution. As today's society consumes large amounts of fuel, the energy industry is affecting the infrastructure and maintenance of all civilizations across the globe. Transportation of oil and natural gas through a pipeline system proves to be most efficient and safe. Most pipelines are made from steel. The quality and properties of steel used in this field are determined by the environmental safety requirements and industry regulations. The majority of steel pipe carrying oil and natural gas is the low representation of carbon and other alloys such as manganese and silicon. Manufacturers of this kind of steel have a stringent focus on quality testing such as tensile strength ratio, toughness and hardness. The purpose of this contribution is to focus on the microstructural anisotropy caused by chemical segregation and non-uniform distribution of inclusions in X65 pipeline steel, with focusing on the toughness properties and microstructural analysis.

Keywords: Toughness, microstructure, inclusions, pipeline steel, segregation.

\section{Introduction}

High grade pipeline steels are manufactured by using thermomechanical controlled rolling after which the product gains superior characteristics by controlling the deformation and the temperature of deformation during the hot rolling process. Thanks to the effect of plastic deformation above and below the recrystallization stop temperatures a fine grained microstructure is created with improved mechanical properties such as toughness and yield strength (Table 1) [1 and 2].

Typical microstructure of hot rolled low alloy steel is illustrated in Fig. 1. It can be seen that the microstructure consists of planner patches of pearlite parallel to the rolling plane. Microstructural banding is often more pronounced in sections containing the rolling direction than in those containing the transverse direction [1].
These patches of pearlite are produced by homogenization of carbon during cooling through the austenite phase field. However, there are gentle variations which occur with the content of manganese, as carbon maintains a uniform chemical potential in the austenite. Manganese lowers the activity of carbon and hence the regions which are rich in manganese are associated with somewhat higher carbon concentration (Fig. 2) [1].

If the region contains relatively large sulphur concentrations, manganese sulphides then precipitate in the regions containing a large average concentration of manganese. As a consequence, manganese is bound in the sulphide which is surrounded by a manganese depleted zone where ferrite forms. The ferrite partitions carbon into the adjacent zones which have low average concentration of manganesethat transforms into pearlite. The position of ferrite bands is thus shifted into locations where the average Mn concentration is large, but where the $\mathrm{Mn}$ is tied up as sulphides (Fig. 3) [1 and 3].

API specifications for X65 pipeline steel

Table 1

\begin{tabular}{|c|c|c|c|c|c|c|}
\hline Grade & C & Mn & P & S & Nb & V \\
\hline X65 & $\leq 0.26$ & $\leq 1.46$ & $\leq 0.04$ & $\leq 0.05$ & $\geq 0.005$ & $\geq 0.005$ \\
\hline Grade & \multicolumn{2}{|c|}{ EUL (MPa) } & \multicolumn{2}{c|}{ UTS (MPa) } & \multicolumn{2}{c|}{ Y/T Ratio } \\
\hline X65 & \multicolumn{2}{|c|}{$\geq 448$} & \multicolumn{2}{c|}{$\geq 0.90$} \\
\hline
\end{tabular}

\footnotetext{
* ${ }^{1}$ Jozef Broncek, ${ }^{2}$ Peter Jankejech, ${ }^{2}$ Peter Fabian, ${ }^{3}$ Norbert Radek

${ }^{1}$ Department of Design and Mechanical Elements, Faculty of Mechanical Engineering, University of Zilina, Slovakia

${ }^{2}$ Department of Technological Engineering, Faculty of Mechanical Engineering, University of Zilina, Slovakia

${ }^{3}$ Department of Operation Engineering, Faculty of Mechatronics and Machine Design, Kielce, University of Technology, Poland

E-mail: jozef.broncek@fstroj.uniza.sk
} 

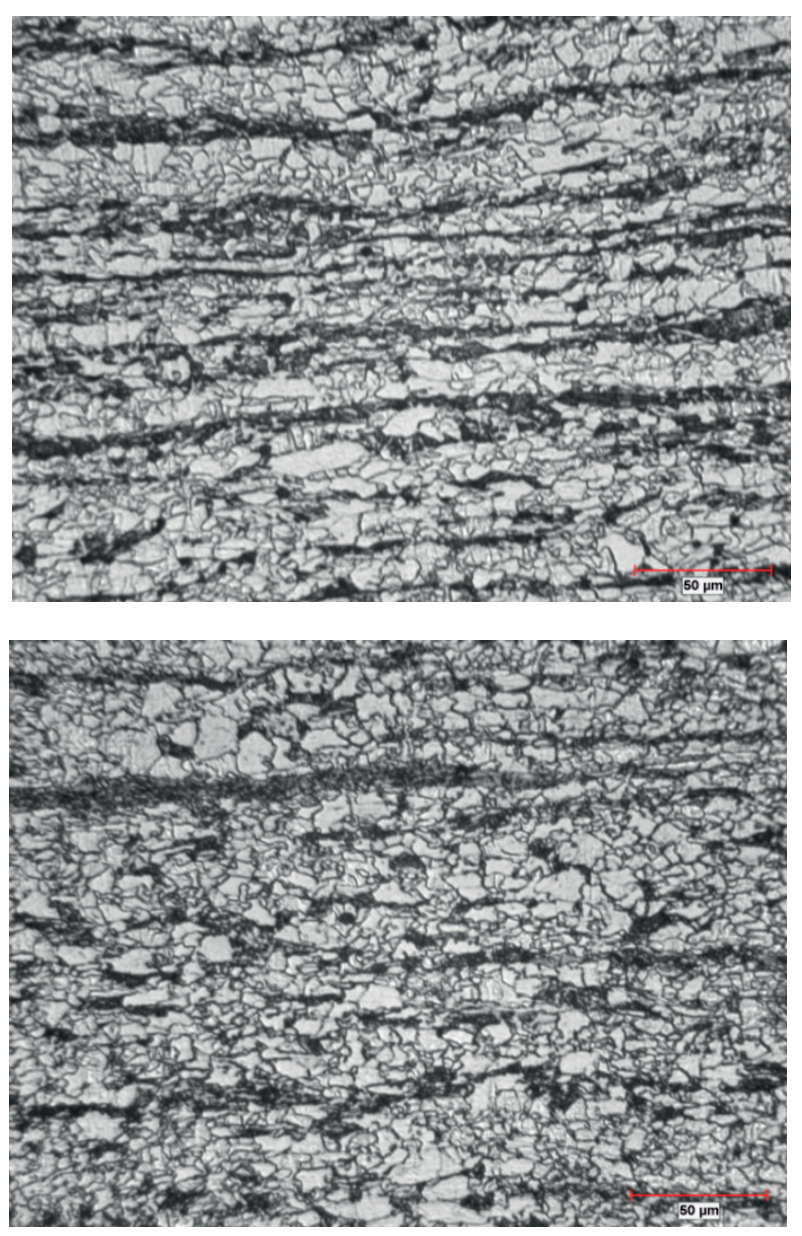

Fig. 1 Typical microstructure of hot rolled steel, in this case grade X70

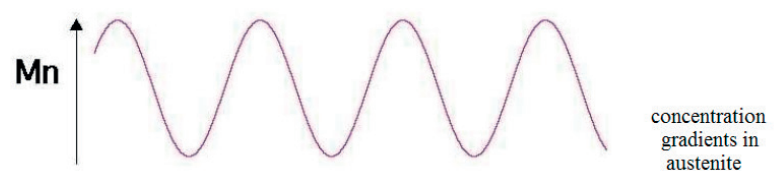

$\mathrm{C}$

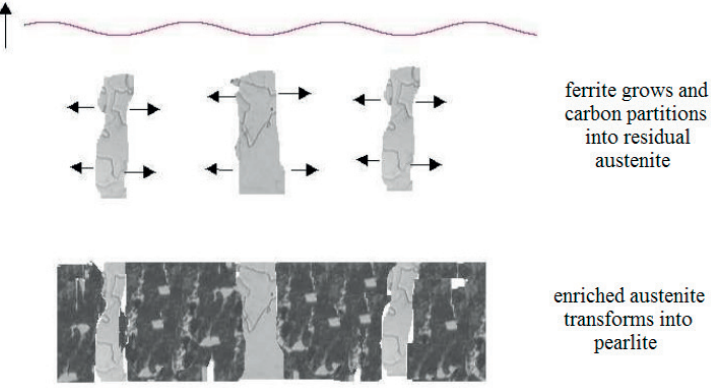

Fig. 2 Illustration of mechanism banding where locations with higher concentration of manganese become pearlite bands [1]

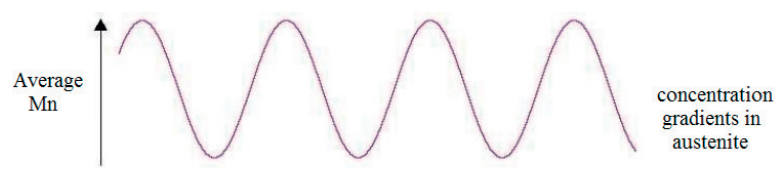

$c \uparrow$

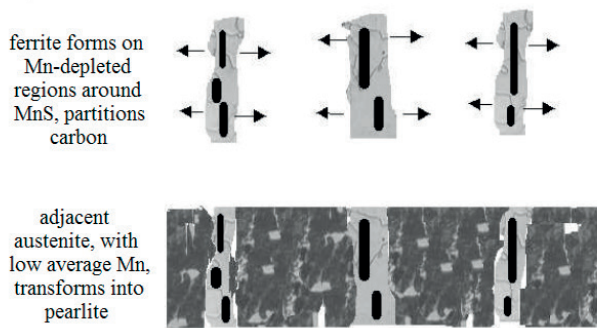

Fig. 3 Illustration of mechanism banding where steel contains substantial quantities of manganese sulphides [1]

\section{Influence of anisotropy on mechanical properties}

The orientation dependence of toughness is a well-known phenomenon for hot-rolled steels in general. There are three particular factors which influence mechanical properties of hot rolled steels:

- non-uniform distribution in the size and shape of inclusions,

- microstructural anisotropy due to chemical segregation with banding,

- elongated grain structure.

Inclusions influence anisotropy because they are often associated with the initial solidification process and any solidification inducted chemical segregation. Others may participate in the austenite at high temperatures prior to the hot deformation that the cast steel is subjected to. Common inclusions include the manganese sulphides, silicates and alumina and combinations of oxides depending on the particular steelmaking route; the hot deformation needed to shape the steel has the effect of orienting these phases along the principal plastic strain directions (Fig. 4). Some phases such as manganese sulphides and silicate can deform along with the steel and hence become elongated, whereas others fragment and form stringers along these same directions. The inclusions can, as a consequence, lead to a variety of anisotropies, particularly with respect to tensile elongation, bend properties, fracture mode and fracture toughness [1, 4, 5, 3, 6, 7, 8 and 9].

Nonmetallic inclusion like $\mathrm{MnS}$ influence properties by nucleating cleavage or voids. It is often that the inclusions serve to concentrate stress so that adjacent and more brittle cementite particles can initiate cleavage (Fig. 5) [1, 2 and 3]. 


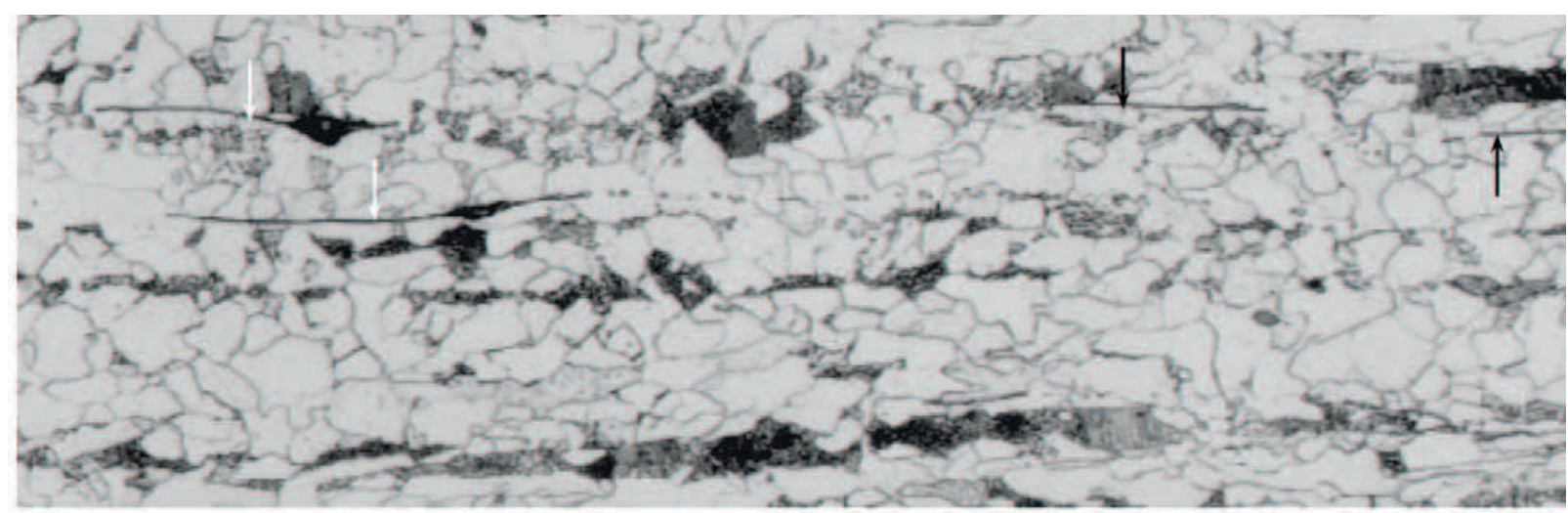

Fig. 4 Low carbon microalloyed steel consisting of ferritic grains, pearlite bands and flattened MnS (black arrows) and mixed oxide $\mathrm{MnS}$ (white arrows) [1]

This is because inclusions like MnS can lose cohesion with the matrix before the onset of cleavage. The tip of elongated inclusion provides the greatest stress concentration so loading normal to the plane of the inclusion leads to poor toughness in contrast to the case where the principal lading is parallel to the long axis when the stress concentration due to decohesion is of minor importance. This leads to anisotropy of toughness [1 and $10]$.

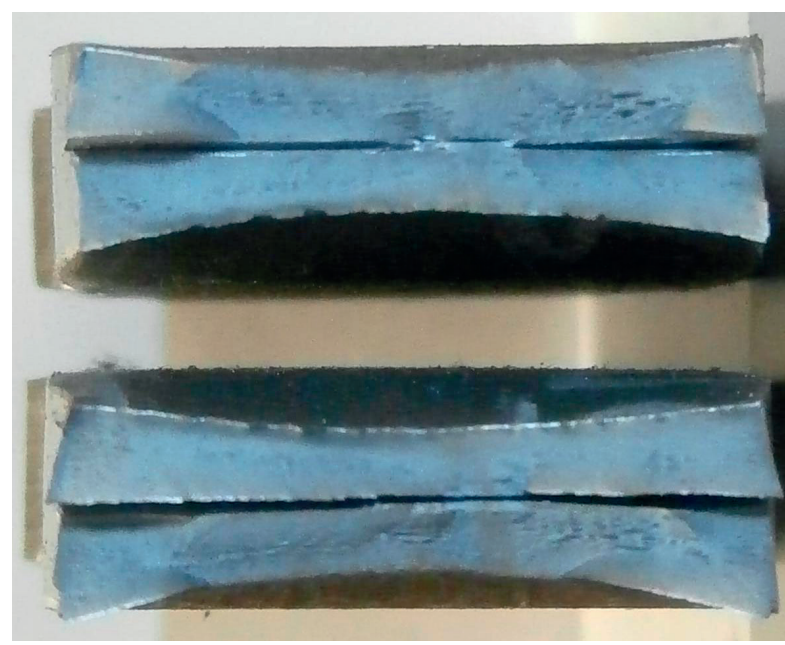

Fig. 5 Broken tensile specimen of X65 pipeline steel where the cleavage is initiated by nonmetallic inclusions

\section{Experimental part}

The material for testing was a pipe made from hot rolled microalloyed steed X65 whose chemical composition is shown in Table 2. This type of pipeline steel permits fluids to be transmitted at higher pressures with vital toughness and tensile properties, amongst other factors especially in ensuring susceptibility due to hydrogen inducted cracking (HIC) which is caused by hydrogen sulphide gas.

The samples for impact testing were cut from the pipe as shown in Fig. 6. The set of samples marked by letter A represent the transverse orientation to the rolling direction (elongated grains) and set of samples marked by letter B represent longitudinal orientation that means parallel to the direction of rolling. One set contained three machined samples. The testing temperature was $-45^{\circ} \mathrm{C}$. Measured values are recorded in Table 2 and graphically illustrated in Fig. 7.
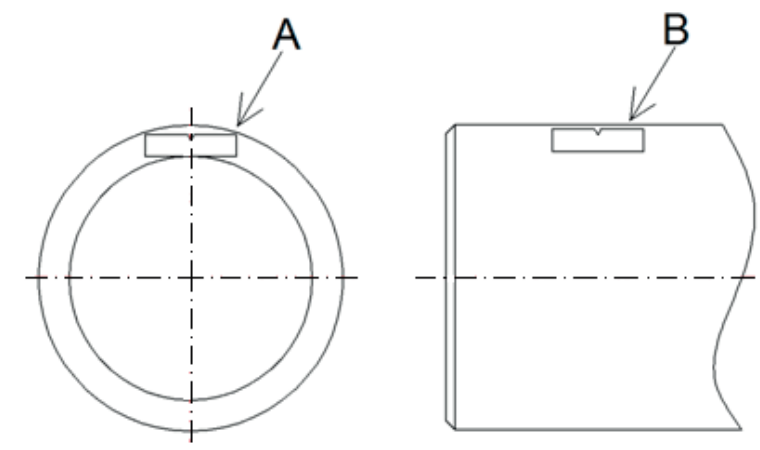

Fig. 6 Illustration of $C V N$ sample orientation in the experimental material

Chemical composition of tested $\mathrm{X} 65$ pipeline steel

Table 2

\begin{tabular}{|c|c|c|c|c|c|c|c|c|c|c|c|c|}
\hline $\mathrm{C}$ & $\mathrm{Si}$ & $\mathrm{Mn}$ & $\mathrm{P}$ & $\mathrm{S}$ & $\mathrm{Co}$ & $\mathrm{Ni}$ & $\mathrm{Cr}$ & $\mathrm{Mo}$ & $\mathrm{V}$ & $\mathrm{Nb}$ & $\mathrm{Ti}$ & $\mathrm{B}^{*}$ \\
\hline 0.07 & 0.25 & 1.39 & 0.013 & 0.001 & 0.01 & 0.01 & 0.04 & 0.01 & 0.05 & 0.05 & 0.01 & $<1$ \\
\hline
\end{tabular}

$* x .1000$ 


\section{COMMNICOIIONS}

Measured values from impact testing

Table 3

\begin{tabular}{|c|c|c|c|c|c|c|c|c|c|}
\hline Specimen size & Specimen & Temp. & \multicolumn{3}{|c|}{ Specimen markings } & \multicolumn{3}{|c|}{ Absorbed energy ( $\mathrm{J})$} & Average absorbed energy \\
\hline $55 \times 10 \times 10$ & Transverse & -45 & A1 & A2 & A3 & 217.0 & 235.7 & 222.3 & 225 \\
\hline $55 \times 10 \times 10$ & Longitudinal & -45 & B1 & B2 & B3 & 245.6 & 247.0 & 273.0 & 255 \\
\hline
\end{tabular}

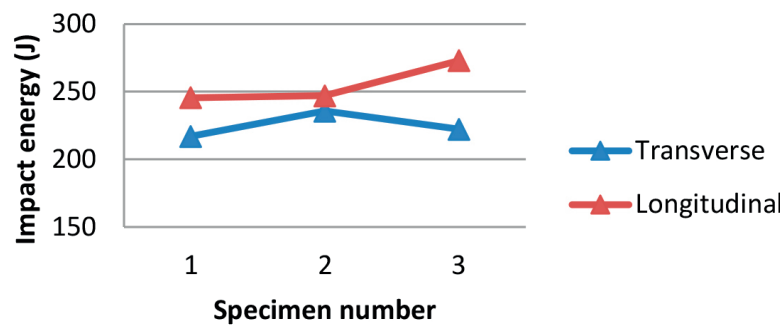

Fig. 7 Graphical illustration of measured values from impact testing

\section{Conclusion}

The purpose of this contribution was to find out how big the influence of chemical segregation and inclusions on toughness of examined X65 pipeline steel is. From the measured values (Table 3 ) it is possible to suggest that the toughness is higher parallel to rolling direction than in the transverse direction. The next phenomena which can be observed are splits on broken surfaces of the CVN specimens (Fig. 8) and tensile specimen (Fig. 5).

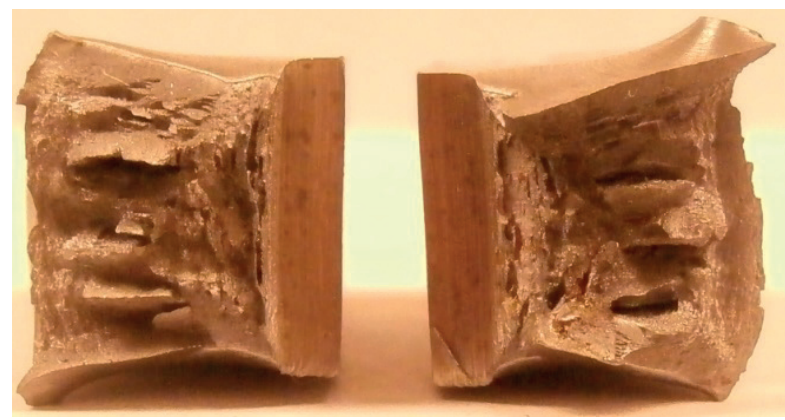

A1 Transverse

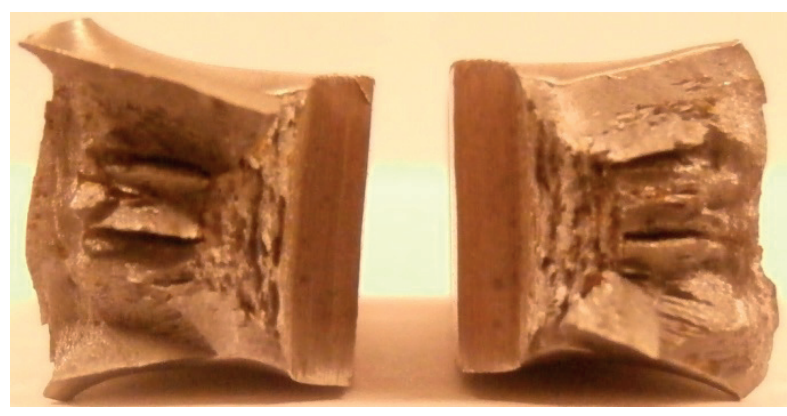

A2 Transverse

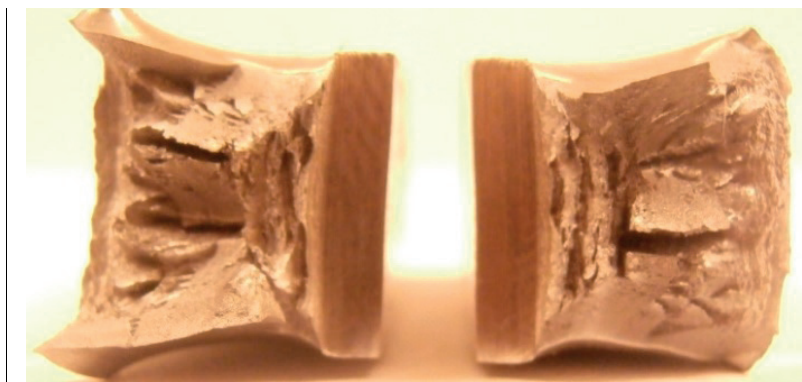

A3 Transverse

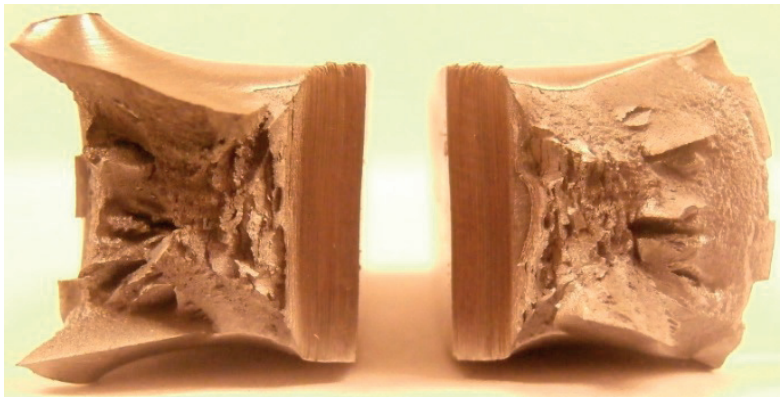

B1 Longitudinal

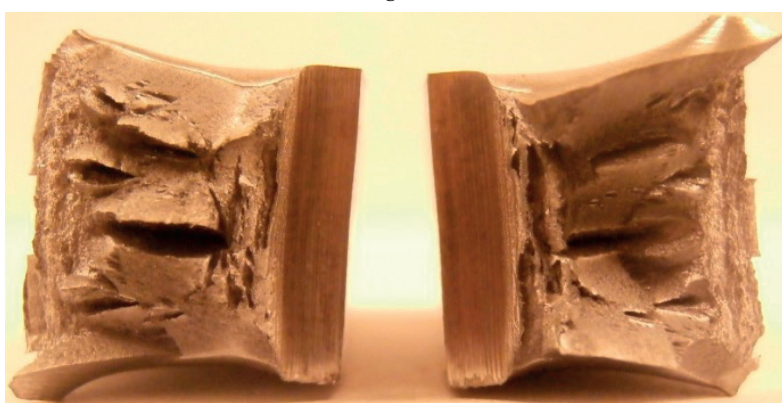

B2 Longitudinal

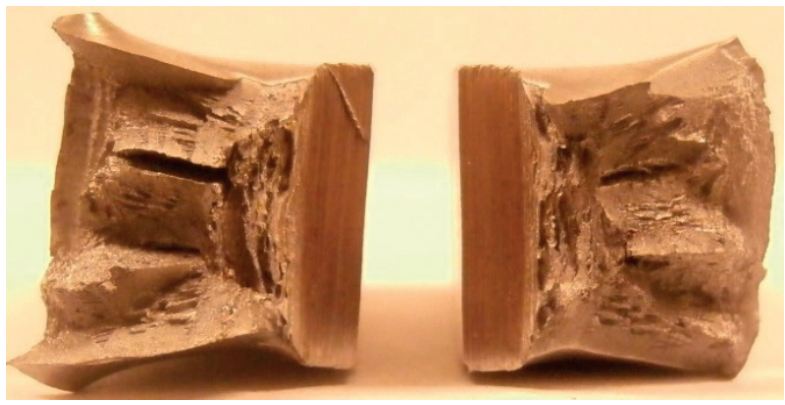

B3 Longitudinal

Fig. 8. Broken samples from Charpy impact testing 
These splits can be caused by elongated inclusions such as manganese sulphides or by delamination. Due to the fact that the examined steel contains a little amount of sulphur $(0.001 \%)$ it can be assumed that the main cause of splitting is delamination. Delamination is caused by the presence of microstructural banding with variations in crystallography between adjacent bands. As we can see in Figs. 9 and 10 these bands are located in the longitudinal and transverse direction of the examined steel. The difference is that the bands in the transverse orientation are more discontinuous than in the longitudinal direction. This is because the bands are more elongated with the grains in the process of hot rolling.

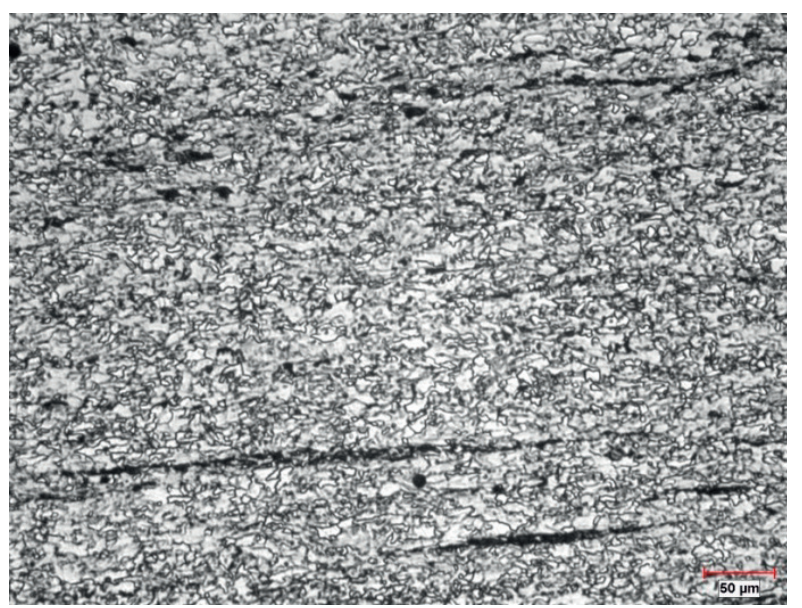

$100 x$

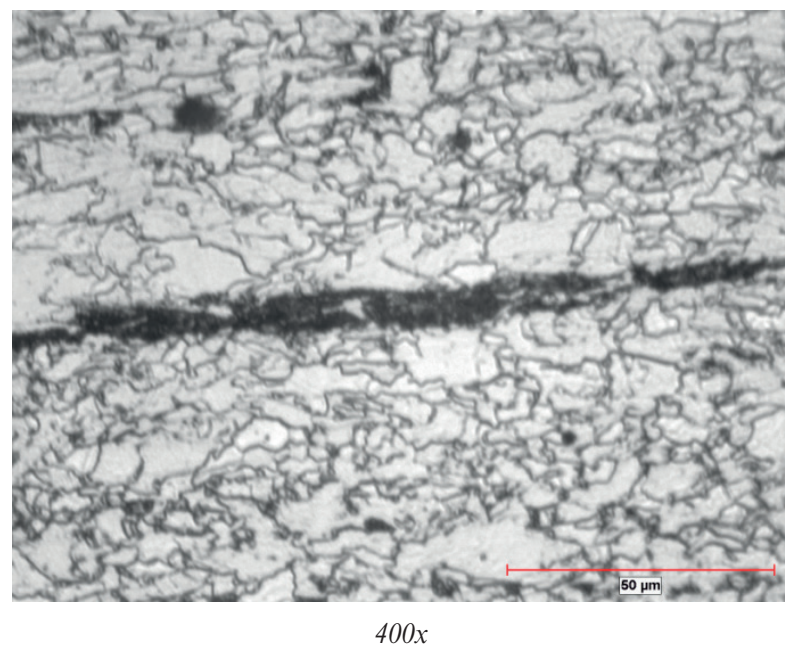

Fig. 9 Microstructural bandings in the transverse orientation of elongated grains, Nital $2 \%$

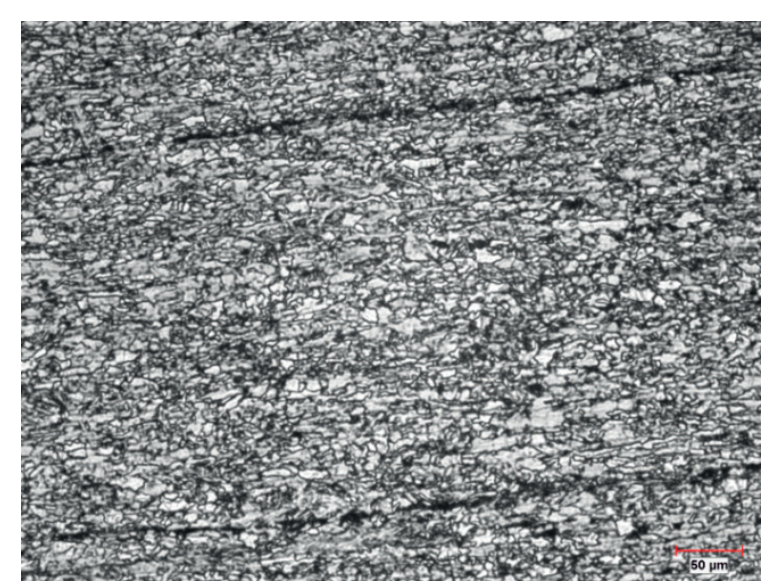

$100 x$

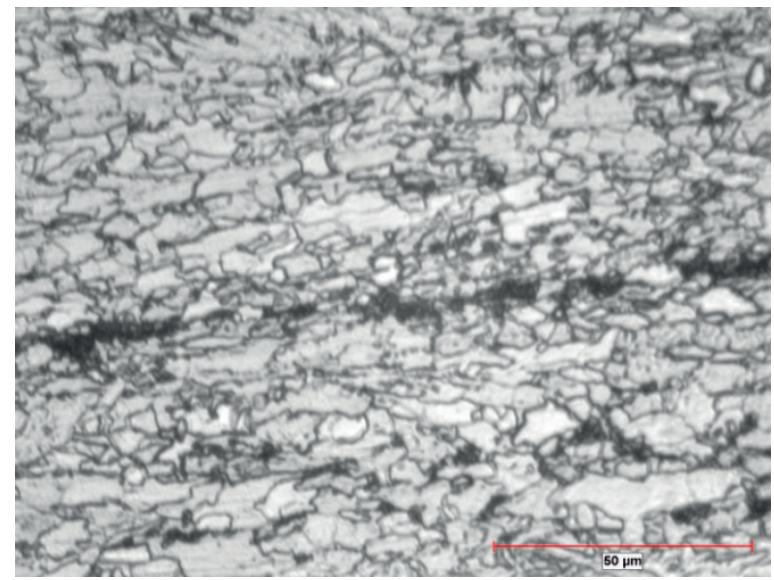

$400 x$

Fig. 10 Microstructural bandings in the longitudinal orientation of elongated grains, Nital 2\%

To mineralize the forming of these patches, manufacturers are trying to decrease the amount of phosphorus and sulphur to minimum. Also new methods of hot rolling (cross rolling) were developed to control the shape of the inclusions in combination with adding elements like zirconium, cerium and titanium. Thanks to these methods the anisotropy is reduced to the point that the thermo-mechanically rolled steels like grade X65 can meet the safety requirements.

\section{Acknowledgments}

The research work reported here was made possible by the project "Research Centre of University of Zilina", ITMS 26220220183. Assistance provided by Prooftest Consulting Inc. was also highly appreciated. 


\section{COMMNICOIIIONS}

\section{References}

[1] JOO, M., SUH, D., BHADESHIA, K.: Mechanical Anisotropy in Steels for Pipelines. 2013, [online], (cit. 27.02.2015), http://www.msm.cam.ac.uk/phase- trans/2013/anisotropy_Joo_ISIJ_2013.pdf

[2] BREZinOVA, J., GUZANOVA, A., MARUSCHAK, P., LORINCOVA, D.: Study of Wear Processes of Weld Clads, Acta Metallurgica Slovaca, vol. 20, No. 2, 2014, pp. 167-176, DOI 10.12776/ams.v20i1.273, ISSN 1335-1532

[3] KONAR, R., MICIAN, M.: Numerical Simulation of Residual Stresses and Distortions in Butt Weld in Simulation Programme SYSWELD, Communications - Scientific Letters of the University of Zilina, vol. 14, No. 3, 2012, pp. 49-54, ISSN $1335-4205$

[4] RICHTARECH, L - BOLIBRUCHOVA, D.: Study of the Gas Content in Aluminium Alloys, Manufacturing Technology: J. for Science, Research and Production, vol. 13. No. 1, 2013, pp. 14-20, ISSN 1213-2489

[5] PASTIRCAK, R.: Effect of Low Pressure Application during Solidification on Microstructure of AlSi Alloys, Manufacturing Technology: J. for Science, Research and Production, vol. 14. No. 3, 2014, pp. 397-402, ISSN 1213-2489

[6] PETRU, M., BRONCEK, J., LEPSIK, P., NOVAK, O.: Experimental and Numerical Analysis of Crack Propagation in Light Composite Materials under Dynamic Fracture. Communications - Scientific Letters of the University of Zilina, vol. 16, No. 3A, 2014, pp. 82-89, ISSN 1335-4205

[7] BREZINOVA, J., GUZANOVA, A., DRAGANOVSKA, D., BRONCEK, J.: Quality Evaluation of HVOF Coatings on the Basis of WC-Co in Tribocorrosive Conditions, Material Science Forum, vol. 811, 2015, DOI 10.4028/www.scientific.net/MSF.811.63 pp. 63-66

[8] KOHAR, R., HRCEK, S.: Dynamic Analysis of a Rolling Bearing Cage with Respect to the Elastic Properties of the Cage for the Axial and Radial Load Cases. Communications - Scientific Letters of the University of Zilina, vol. 16, No. 3A, 2014, pp. 74-81, ISSN 1335-4205

[9] HRCEK, S., KOHAR, R., MEDVECKY, S.: Usage of Dynamic Analysis to Determine Force Interactions between Components of Rolling Bearings. Communications - Scientific Letters of the University of Zilina, vol. 14, No. 3, 2012, pp. 62-67

[10] KONAR, R., PATEK, M., MICIAN, M.: Experimental Measurements and Numerical Simulation of Bridge Construction Welding at Low Temperatures, Communications - Scientific Letters of the University of Zilina, vol.16, No. 3A, 2014, pp. 130-135, ISSN 1335-4205. 